\title{
CELEBRACIONES FAMILIARES EN AL-ANDALUS (1)
}

\author{
Por \\ M. ${ }^{a}$ MAGDALENA MARTINEZ ALMIRA
}

En el ámbito de las fiestas musulmanas existe un importante capítulo dedicado a festejar los principales acontecimientos familiares. El nacimiento de un hijo, la acogida por parte de la comunidad de un nuevo miembro, el matrimonio e incluso el fallecimiento de un ser allegado, suponer una serie de celebraciones afectadas por un fuerte carácter religioso, y en el caso presente islámico. Los musulmanes celebran estos acontecimientos conforme a los ritos recomendados por la tradición, lo que permite dar un sentido religioso a todos aquellos momentos trascendentales en la vida del creyente.

El nacimiento es sin duda el punto de partida en la vida del creyente musulmán; éste entra a formar parte en la comunidad islámica desde el momento en que ve la luz, como así se recoge en el hadit (2): "La criatura cuando grita la primera vez es un servidor de Dios». La comunidad islámica reconoce al nuevo miembro mediante el ritual de la imposición del nombre o Tasmiyya. La tasmiyya consiste en dar el nombre al recién nacido siendo el padre, tutor o persona autorizada la encargada de realizarlo. Seguidamente, se pronuncia al oído del neonato el cadan, llamada a la oración o bien se sustituye por cualquier fórmula pía reconocida por la tradición.

La imposición del nombre (3) tiene lugar el séptimo día del nacimiento y suele festejarse con el sacrificio de una res. El sacrificio se denomina ${ }^{C} A K T$ ka y según el hadít (4) es práctica tradicional recomendable imponer en el transcurso de ese día el nombre al recién nacido, cortarle el cabello y sacrificar

(1) El presente trabajo forma parte de mi Memoria de Licenciatura, defendida el mes de octubre de 1986 en la Universidad de Alicante y realizada bajo la dirección del Dr. Mikel de Epalza.

(2) Nido y Torres, M. del, Derecho Musulmán, Tetuán, 1927, pág. 24.

(3) En relación a las distintas partes del nombre que se imponen durante la tasmiyya, consultar Pareja, $F$. M Islamologia, t. II, pág. 548.

(4) Al-Qayrawåni, La Risāla, Alger, 1971, cap. XXIX 
un macho cabrío. El animal contará como mínimo con ocho meses de edad, en el caso de ser un ovino; será de más de un año si es caprino; y de por lo menos cuatro años si el animal en cuestión, es bovino. En cualquier caso, se prefiere efectuar el sacrificio de un animal no castrado y si lo estuviese, éste es mejor que una hembra.

En cuanto a la fecha exacta para la celebración de la tasmiyya, recomienda la tradición efectuarla durante el séptimo día después del nacimiento, si bien, en el caso de no ser posible podría posponerse incluso hasta el momento en que el niño haya alcanzado la mayoría de edad y tenga capacidad para hacerlo voluntariamente. El festejo ha de tener lugar por la mañana y consistirá en la celebración de una comida familiar, denominada walima considerada por algunos juristas obligatoria. Recomienda la tradición repartir el peso de los cabellos cortados al recién nacido en oro y plata entre las personas más necesitadas.

En Al-Andalus, siguiendo los preceptos de la escuela malikí, se celebraban suntuosos festejos con motivo del nacimiento de los herederos al trono; fiestas que eran mucho más modestas cuando del pueblo llano se trataba. En relación con las primeras tenemos el testimonio de Ar-Razì quien escribió sobre el nacimiento del heredero Al-Hakam y de los festejos con tal motivo celebrados (5): "Su nacimiento tuvo lugar en el alcázar de Córdoba en viernes, en el momento de la llamada a la oración cuando el orador empezaba el sermón; a primeros de rayab de este año (20 de enero del 915); su padre se holgó mucho de su nacimiento, gastándose grandes sumas en la fiesta de su primer corte de cabellos y recibiendo felicitaciones de la gente, cuyos poetas abundaron en presagios de su buena estrella».

La circuncisión o Hitân es otro de los festejos propios en el mundo islámico. La circuncisión es considerada signo distintivo del musulmán, pudiendo ser practicada hasta la edad de siete años. En Al-Andalus se sabe que era motivo de reunión familiar, invitando el padre del circuncidado a sus amigos para festejar el acontecimiento. Consistía la celebración en reunir a unos cuantos niños de edades similares pertenecientes a la misma o diferentes clases sociales, con el fin de ser circuncidados.

La circuncisión es cosiderada por juristas como Al-Qayrawānī y Al-Šafī-'T obligatoria, si bien la mayoría de los estudiosos la consideran simplemente recomendable. También era recomendable la celebración de un banquete o ${ }^{1}$ dar con el fin de honrar a los asistentes. Tras el banquete, los andalusíes, siguiendo la tradición malikí, celebraban festines fastuosos en los que se recitaban qasidas-panegíricos, conocidas como idariyyas, cuyo fin era felicitar al monarca que generosamente regalaba a sus súbditos con motivo de la circuncisión del heredero.

lía fiesta de la circuncisión constaba a su vez de carreras de caballos,

(5) Ar-Razi, Anales Palatinos del Califa de Córdoba Al-Hakam II, Madrid, 1967, pág. 40. 
disparo de fuegos artificiales, representaciones teatrales de sombras chinescas e incluso actuaciones de funambulistas, como así relata Ibn Zamrak con motivo de la circuncisión de hijos y nietos de Muhammad $V(6)$. Otro relato muy clarificador es el efectuado por Ar-Razi con motivo de la circuncisión de uno de los hijos de los Hasaníes, fiesta que corrió a cargo de Al-Hakam II (7): "Los hasaníes acogidos al aman del califa Al-Hakam, circuncidaron a unos hijos suyos en la alcunia de Al-Mutani, el Califa tomó para sí todo el gasto al día siguiente y ordenó en la casa de ellos se celebrase un solemne festín y que estuviese muy concurrido y se invitase a éste a las gentes principales. Confió esta misión al visir zalmedina de Córdoba, quien ensanchó el radio de la fiesta y la dispuso con el mayor orden. Fueron invitados todos los miembros de la tribu de los Qurays y los principales jefes y caballeros beréberes, así como una representación de los vecinos principales de Córdoba y de los ricos del zoco. Se les dió de comer y después de incensarlos se les cubrió la cabeza de algalia pura».

El siguiente acontecimiento importante en la vida del musulmán es el matrimonio, y sin duda el de mayor solemnidad. El Corán afirma que el matrimonio es práctica recomendable (8): "Dios Clemente y Misericordioso dijo: Casad a los que aún no estén casados. A vuestros criados pobres con vuestras criadas; si son pobres Dios les hará ricos" y más adelante en la Sura XXX V. 20/21 (9) dice: "Entre sus aleyas está el que creó, sacándolas de vosotros mismos, esposas para que en ellas reposeis. Entre vosotros ha establecido el amor y el cariño. En eso hay aleyas para gentes que reflexionan». La Sunna aduce al respecto: "El matrimonio es una orden de Dios y debeis cumplirla", y en este mismo sentido Malik lbn Anàs basándose en la necesidad de procrear afirma (10): «El matrimonio es casi obligatorio, porque el hombre ha sido creado para tener familia».

En relación a las condiciones necesarias para la validez de un matrimonio, Al-Qayrawānī propone como primaria la existencia de un tutor matrimonial o wali, cuya función es la de representar a una mujer de condición libre. El tutor puede ser el padre, abuelo paternos, los hermanos o cualquier pariente próximo de línea paterna así mismo en el caso de esclavos, puede el amo desempeñar esta función. Ahora bien, de entre los anteriormente citados sólo el padre tiene autoridad para casar al hijo sin su consentimiento, tal como manifiesta Ibn Qudāmā (11).

La segunda condición de validez es el ofrecimiento de una dote o sadâq, cuya mínima cuantía será de 1/4 dinar de oro. La importancia de la dote es ratificada por Mālik Ibn Anàs al considerarla (12): "Una de las columnas del

\footnotetext{
(6) García Gómez, E., Cinco poetas musulmanes, Madrid, 1944, pág. 169-245. Sobre la circuncisión ver Peres, H., La poesie Andalouse en Arabe clasique au Xle siécle, París, 1937, págs. 294, 367, 382.385.

(7) Ar-Razĩ, op. cit.

(8) Nido y Torres, M. del, op. cit. pág. 31.

(9) Vernet, J. El Corán, Barcelona, 1963, pág. 421

(10) Nido y Torres, M. del., op. cit. pág. 43.

(12) Nido y Torres, M. del., op. cit. pág. 43.
} 
matrimonio". La dote ha de ser entregada por el marido al tutor o a la persona que el padre haya designado como tal. Desde el momento de la donación la mujer se considera propiedad del marido y en caso de disolución matrimonial el derecho prevee la devolución de la dote.

La tercera condición de validez en la celebración de un matrimonio es la presencia de testigos de perfecta honorabilidad, testigos que se denominan adules y cuyas pricipales cualidades han de ser la justicia, mayoría de edad y condición libre.

Desde el punto de vista meramente religioso las fiestas nupciales suponen la resolución del contrato matrimonial, conocido como caqd al-nikāh. acto que tiene lugar en la mezquita después del ocaso y que es presidida por el mumlīk, quien dirige una alocución, huṭba, a los presentes y exhorta al novio a aceptar el matrimonio. El asentimiento sobre el contrato concluye con la pronunciación de la Fātiḩa.

En Al-Andalus los festejos del matrimonio, curs, curus y cumra, eran similares a los celebrados en el Magreb y en Oriente, prolongándose las fiestas durante una semana, acontecimiento familiar que comportaba un fastuoso ceremonial. Cuando una mujer encontraba entre sus amistades la joven doncella que creía adecuada para su hijo, se lo comunicaba a éste, y si a él le parecía apropiada, la madre entraba en contacto con la futura desposada, con el fin de acordar la dote. Se fijaba la composición del ajuar de la novia que comprendía ropa de la casa y vestidos, así como joyas y alfombras en caso de que la novia perteneciese a una clase social elevada (13). Concluidos los preliminares se comunicaba al padre el nuevo acontecimiento, quien a su vez, debía concertar con el tutor matrimonial el día en el que se pediría a la novia, formalizándose el contrato. En opinión de Ibn Qudâmâ al matrimonio (14): «... es recomendable darle cierta publicidad y en esta ocasión, hacer sonar el tamborín por parte de las mujeres». Todo ello permite afirmar que la tradición islámica debía considerar lícitos estos festejos y manifestaciones públicas, manifestándose transigentes con la alteración del orden que un acontecimiento de tal envergadura suponía en cualquier ámbito y clase social.

La novia recibía las felicitaciones de sus amistades durante la primera semana posterior a la fijación de las cláusulas del contrato, momento en el que era conducida a casa del marido, rodeada por un cortejo al son de la música. Al cortejo seguían mulas que portaban el ajuar. El marido, por su parte, celebraba un festín con los amigos (15); sobre el anterior se pronunciaron eminentes juristas entre los que cabe citar Al-Saqati quien entre las obligaciones del almotacen señala la de vigilar a ciertas personas durante la celebración de los festejos (16): "Será severo con los afeminados (muyannatin, cantores

(13) Arie, R., L'Espagne musulmane au temps des nasrides (1232-1492). París, 1963, pág. 365.

(14) Ibn Qudâmâ, Le prècis de droit musulman d'lbn Qudâmâ, Beirut, 1950, pág. 169.

(15) Ibn Qudâmâ, op. cit. pág. 222.

(16) Chalmeta Gendrón, P., "Libro del buen gobierno del Zoco», Al-Andalus XXXII, Madrid, 1967, I. 
que imitan a las mujeres con sus voces y trajes) para que no se dejen crecer los aladares, ni asistan a los banquetes de bodas ni funerales..." Ibn "Abdūn hace otra aportación valiosa de carácter jurisdiccional al afirmar (17): «El cocinero, contratado para un festín de bodas (wālima) no deberá tomar nada de comida, pues sería un robo y trapacería, a menos que sea condición determinada que haya impuesto de antemano el que da el festín, o que se trate de un regalo que le hace el novio".

Con respecto a la asistencia a un festín nupcial Ibn Qudama dice (18): "Es un deber aceptar una invitación. El Profeta ha dicho: "no aceptarla es desobedecer a Dios y a su Profeta; aquellos que no quieran tocar la comida que se les ofrece dirigirán una oración a Dios y se marcharán».

Opinión a tener en cuenta es la de Mālik Ibn Anàs quien en relación con las fiestas nupciales se pronunció del siguiente modo (19): "Hay que aceptar las invitaciones de comida, si no comportan diversiones prohibidas manifiestamente o actos reprensibles". Así mismo conviene referirse a las prohibiciones explícitas de la tradición a que los maestros asistieran a festines de boda, argumentando que la asistencia a los mismos suponía pérdida de tiempo para los niños a quienes instruían, y consecuentemente pérdida de dinero para sus padres. La normativa musulmana sobre festejos nupciales afectó por igual a las distintas clases sociales andalusíes, sometidas a los preceptos jurídicos de la escuela malikí.

La defunción marca el contrapunto con respecto a las fiestas descritas anteriormente. Asignar a un hecho luctuoso un contenido festivo puede parecer paradójico, sin embargo hay que comprender que para el creyente musulmán la muerte es la entrada en la morada de Alà; morada a la que llega en virtud de su comportamiento terrenal.

El fallecimiento de un musulmán va precedido de un ritual cuya finalidad es hacer llegar con prontitud al fallecido a su última estancia. Los ritos funerarios poseen un fuerte contenido meritorio, tanto para el agonizante como para quienes en beneficio del primero, cumplimenten los preceptos religiosos establecidos por la tradición musulmana. Así Al-Qayrawani afirma que la oración del difunto o șalāt cala l-mayyit, y la participación en los funerales son obligatorios para cualquier musulmán. Recomienda el mismo autor en su Risā la (20) volver al agonizante hacia la qibla, posición que conservará hasta su ubicación en la última morada. En el momento de la defunción se le cerrarán los ojos y la boca, procurando que el fallecido esté en estado de pureza espiritual y cubiertas todas las partes de su cuerpo, evitando se aproxime a él cualquier persona impura. No reprueban los juristas que se manifieste dolor por la pérdida de un ser querido mediante el llanto, pero sí que tales manifesta-

(17) García Gómez, E., Sevilla a comienzos del siglo II, Sevilla, 1981

(18) Idem not. 17.

(19) Al-Qayrawänī, op. cit. cap. XLII

(20) Al-Qayrawānī, op. cit. cap. XX. 
ciones se acompañen de gritos y lamentos; lo que por otro lado demuestra que se realizaba sobre todo en las clases sociales más pobres, cuyas mujeres (21): "Daban gritos y lamentos, se golpeaban el pecho y las mejillas".

El segundo rito preceptivo es el lavado del difunto, que debe realizarse un número impar de veces, cubriendo las partes prohibidas (caura) del cuerpo y presionando el vientre del fallecido; en ningún momento se cortarán las uñas y cabellos ni tampoco se peinará al fallecido. Durante este ritual se envolverá la mano en una servilleta para lavar seguidamente los orificios naturales del muerte; es recomendable, pero no obligatorio, practicar las abluciones rituales sobre él. Se le lavará la cabeza y la barba, concluyendo con el costado derecho y el izquierdo, en este mismo orden. El lavado ha de ser con agua y loto. El rito se repetirá hasta tres veces, siendo secado con la ayuda de un lienzo. Es conveniente perfumar las partes que toman contacto con la tierra durante el šugūd o posternación, así como el resto del cuerpo. En el último lavado es práctica tradicional recomendable aromatizar el cuerpo del

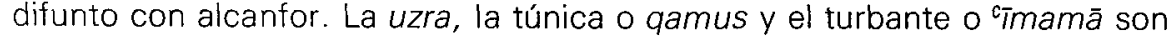
las últimas prendas que llevará el musulmán a la morada final, recomendando la tradición que se le envuelva en estas telas a modo de lienzo; por lo general estas vestiduras constituyen un número impar.

La oración del difunto, șalāt cala /-mayyid, es el rito final de la celebración fúnebre. El imân pronuncia un takbîr y dirige las plegarias. Seguidamente se recita la Fātiha y efectúa un segundo takbîr, a continuación reza la oración dirigida al profeta, que es acompañada por un tercer takbîr; para concluir con un último takbîr y la fórmula de salutación final. La oración del difunto es de estricta obligación, wāğid, recomendando la tradición a los muecines que se haga la llamada a la misma desde la mezquita.

La tradición recomienda que el cortejo fúnebre se dirija a pie hasta el cementerio, portando a hombros al difunto. Es costumbre ofrecer una limosna el día del entierro, zakāt, generalmente en especie y dirigida a los pobres, aplicándose su mérito por el alma del difunto. Así mismo, y durante los nueve días siguientes al fallecimiento, los parientes realizan la hatma o recitación completa del Corán. La recitación la efectúan todos los miembros de la familia, que reciben en sus hogares las muestras de condolencia por parte de conocidos y vecinos. La tradición recomienda realizar los ritos descritos en el momento del fallecimiento y en los días siguientes; en caso de no poder celebrarse, permite sean cumplimentados dentro de un plazo máximo de cuarenta días, durante el que se guardará luto obligatorio.

En Al-Andalus la muerte de un musulmán se caracterizaba por la sencillez y falta de pompa en los ritos fúnebres. Los muecines realizaban la llamada a la oración por el difunto, como recomendaba la tradición (22), siendn

(21) Ariè, R., op. cit., pág. 365 y ss.

(22) Arié, R., op. cit., pág. 365. 
meritorio para el creyente musulmán acudir al sepelio de sus familiares y conocidos.

Al fallecido se le vestía con el cakfän prenda mortuoria sobre la que se envolvía un sudario blanco. El sudario era sustituido por el ihrām si el creyente había tenido la posibilidad de ir a la Meca, aunque estos eran los menos. Antes de proceder a la inhumación, el cortejo fúnebre practicaba una singular ceremonia religiosa: depositaban junto al cadáver la "llamada» (23), consistente en una carta escrita en árabe con azafrán en pergamino o papel, cuya finalidad era prestar fortaleza al difunto para responder a los ángeles de Alà en el juicio al que sería sometido esa misma noche. El cadáver era seguidamente depositado de costado en la tumba, con la cabeza a mediodía y el rostro vuelto a la Meca(24), tal y conforme recomienda la tradición.

En la noche última de los nueve días después del sepelio era recomendable asistir con la ablución y purificación efectuadas. Al concluir la lectura, el alfaquí rogaba por todos los presentes, sus padres, madres y por los descendientes del Profeta, tanto vivos como muertos. La tradición prohibía a las plañideras fuesen al sepelio destocadas y con el rostro descubierto, pudiendo ser reprendidas por ello (25). En el texto de Al-Saqati (26) se especifica la función de la mujer en los cortejos fúnebres: «Serán mujeres quienes salmodien el Alcorán en los funerales de mujeres; caso de que los salmodiadores fuesen varones ciegos, estarán separadas, detrás de una cortina desde donde le puedan oir las mujeres».

Los juristas musulmanes se preocuparon de la vigilancia de los cementerios por parte del qadi y almotacen o al-muhtasib, lugar frecuentado por los creyentes musulmanes los viernes y días festivos; en este sentido se pronuncia Ibn 'Abdūn (27), denunciando situaciones anómalas: "Una de las cosas más importantes que incumben al cadí („Dios le asista!), es velar por los musulmanes, no sólo vivos sino también muertos.... y refiriéndose a la ciudad de Sevilla dice: "Lo peor que ocurre en su cementerio (por el cual nuestros conciudadanos son objeto de censura) es que permite que encima de las tumbas se instalen individuos a beber vino o incluso, en ocasiones, a acometer deshonestidades..." prohibiendo expresamente: "que en los cementerios se instale ningún vendedor (...) ni se consentirá que los días de fiesta se estacionen los mozos en los caminos entre los sepulcros a acechar al paso de las muieres. Esfuércese en impedirlo el almotacén, apoyado por el cadín.

El rito funeral islámico perduró en Al-Andalus tras la caída del Reino de Granada, como así lo pone de manifiesto un relato de Fray Marcos de Guada-

123) Longás, P., Vida religiosa de los moriscos, Madrid, 1915, pág. 300.

124) Torres Baibás, "Cementerios hispanomusulmanes", Al-Andalus, Madrid, 1957, I, pág. 139

(25) Chalmeta Gendrón, P., op. cit. pág. 161.

(26) idern not. 25

(27) Torres Balbas, op. cit. 
lajara recogido por J. Caro Baroja (28), describiendo el entierro de un morisco valenciano, cuya muerte, como reza el texto: "encubrieron al cura dos días; al gual auisado, fue a la casa del difunto y desqueriendo la puerta, halló dentro mucha cantidad de moriscos alrededor del cuerpo con luz sola de un brasero, mucha cantida de vasijas llenas de agua de laurel, romero y naranjo para sus labatorios y un libro en arábigo de su maldito Alcorán... Después procura en aplacarle con tres mil reales, con que les dexase también enterrar a su difunto no en la sepultura eclesiástica, sino en la antigua que tenían preparada cubierta de pámpanos y proveyda de calabaças llenas de agua y cantidad de . pan y passas".

(28) Caro Baroja, J., Los moriscos del Reino de Granada, Ensayo de Historia social, Madrid, 1976, pág 125 yss. 